\title{
Determinants of institutional delivery in Sub-Saharan Africa: findings from Demographic and Health Survey (2013-2017) from nine countries
}

Shewayiref Geremew Gebremichael ${ }^{*}$ (i) and Setegn Muche Fenta

\begin{abstract}
Introduction: Institutional delivery is a major concern for a country's long-term growth. Rapid population development, analphabetism, big families, and a wider range of urban-rural health facilities have had a negative impact on institutional services in Sub-Saharan Africa (SSA) countries. The aim of this study was to look into the factors that influence women's decision to use an institutional delivery service in SSA.

Methods: The most recent Demographic and Health Survey (DHS), which was conducted in nine countries (Senegal, Ethiopia, Malawi, Rwanda, Tanzania, Zambia, Namibia, Ghana, the Democratic Republic of Congo) was used. The service's distribution outcome (home delivery or institutional delivery) was used as an outcome predictor. Logistic regression models were used to determine the combination of delivery chances and different covariates.

Results: The odds ratio of the experience of institutional delivery for women living in rural areas vs urban area was 0.44 (95\% confidence interval (Cl) 0.41-0.48). Primary educated women were 1.98 (95\% Cl 1.85-2.12) times more likely to deliver in health institutes than non-educated women, and secondary and higher educated women were 3.17 (95\% Cl 2.88-3.50) times more likely to deliver in health centers with facilities. Women aged 35-49 years were 1.17 (95\% Cl 1.05-1.29) times more likely than women aged under 24 years to give birth in health centers. The number of ANC visits: women who visited four or more times were 2.98 (95\% Cl 2.77-3.22) times, while women who visited three or less times were twice $(\mathrm{OR}=2.03 ; 95 \% \mathrm{Cl} 1.88-2.18)$ more likely to deliver in health institutes. Distance from home to health facility were 1.18 (95\% Cl 1.11-1.25) times; media exposure had 1.28 (95\% Cl 1.201.36) times more likely than non-media-exposed women to delivery in health institutions.

Conclusions: Women over 24, primary education at least, urban residents, fewer children, never married (living alone), higher number of prenatal care visits, higher economic level, have a possibility of mass-media exposure and live with educated husbands are more likely to provide health care in institutions. Additionally, the distance from home to a health facility is not observed widely as a problem in the preference of place of child delivery. Therefore, due attention needs to be given to address the challenges related to narrowing the gap of urban-rural health facilities, educational level of women improvement, increasing the number of health facilities, and create awareness on the advantage of visiting and giving birth in health facilities.
\end{abstract}

Keywords: Institutional Delivery, Sub-Saharan Africa, Women, DHS

\footnotetext{
* Correspondence: Shewayirefg@gmail.com

Department of Statistics, Debre Tabor University, Debre Tabor, Ethiopia
}

(c) The Author(s). 2021 Open Access This article is licensed under a Creative Commons Attribution 4.0 International License, which permits use, sharing, adaptation, distribution and reproduction in any medium or format, as long as you give appropriate credit to the original author(s) and the source, provide a link to the Creative Commons licence, and indicate if changes were made. The images or other third party material in this article are included in the article's Creative Commons licence, unless indicated otherwise in a credit line to the material. If material is not included in the article's Creative Commons licence and your intended use is not permitted by statutory regulation or exceeds the permitted use, you will need to obtain permission directly from the copyright holder. To view a copy of this licence, visit http://creativecommons.org/licenses/by/4.0/. 


\section{Introduction}

From 2000 to 2017, maternal deaths decreased by 38\%, implying an annual decrease of $2.9 \%$ [1]. The maternal mortality rate (MMR) in developing countries is roughly 40 times higher than in Europe. In 2017, one in every 37 mothers was at risk of maternal death, accounting for roughly $66 \%$ of all maternal deaths worldwide [1, 2]. Sub-Saharan Africa is one sub-region with a very large MMR. With a direct emphasis on reducing maternal mortality, the international community planned and accomplished Sustainable Development Goals (SDGs).

Institutional delivery is a major concern for a country's long-term growth. As a result, the country's government is preoccupied with maternal and newborn welfare. To improve mother and child health, adequate access to health care during and after pregnancy is required [3]. Birth rates in qualified health centers increased from $6 \%$ in 2000 to $28 \%$ in 2016 in Ethiopia [3], from 44\% in 20082009 to $62 \%$ in 2014 in Kenya [4], from $42 \%$ in 1988 to $74 \%$ in 2014 in Ghana [5] and from $51 \%$ in 2010 to $64 \%$ in 2015-2016 in Tanzania [6]. Increased institutional distribution is critical for lowering maternal and infant mortality. The use of institutional health care is failing to develop in all of Sub-Saharan Africa's countries. In suburban areas, access to health care is different. In comparison to urban areas, rural areas were less frequent. The explanation for this was a lack of access, distance, and sufficient equipment [3-6]. The explanation for this was a lack of access, distance, and sufficient equipment.

Fast population growth in Sub-Saharan African countries, a high level of analphabetism, a high birth-related presence, and a higher share of the population living in rural areas, where public health centers are inaccessible, have all had a negative impact on institutional delivery systems. Lower economic development, sluggish investment, decreased productivity, and overweight rural residents continue to afflict the region [7]. Increased health care costs as a result of improved economic growth [8, 9]. Increased health care spending results in less underfive deaths, lower maternal morbidity and mortality, better household health, and less public health complications. Since childbirth is difficult, maternal health is the most important topic among these pick points. Prepresentation and post-presentation (post-natal) ANC visits, as well as useful details on how to care for herself and the infant, are critical for dealing with any problems that arise during childbirth and providing the mother with. Institutional delivery services are influenced by a variety of factors at the individual and community levels. The rate of non-use of institutional delivery services is highest among women with no schooling, low-income households aged 25 to 34 years, who had never married, had never visited an ANC before, and had lived in economically disadvantaged groups [10].
Previous research looked into the factors that influence where a baby is born. However, the national populations of women living in Sub-Saharan African countries have yet to be presented in depth and illustrated. Previous research has shown differences in childbirth between nations, as a result of administrative or other differences. The study's key research issues include those that have been of great importance to institutional provision for women in Sub-Saharan African countries, as well as the determinants (socio-demographic, economic, maternal or other related factors). We are now very inspired to look into the social-demographic, economic, maternal, and institutional distribution characteristics of Sub-Saharan African women.

\section{Methods}

Study setting, data source, and study design

We use data from the most recent Demographic and Health Survey (DHS) to collect institutional delivery services data from nine countries: Senegal in 2017, Ethiopia in 2016, Malawi in 2016, Rwanda in 2015, Tanzania in 2016, Zambia in 2014, Namibia in 2013, Ghana in 2014, and the Democratic Republic of Congo in 2014 (Table $1)$.

The countries were chosen based on data availability and historical significance. Measure DHS gave the authors permission to download and use these data for this report. The DHS survey was a cross-sectional study that used stratified multistage (mostly two-stage) cluster sampling to sample people across the country.

The Population and Housing Census (PHC) sampling frames were used in the Enumeration Areas (PHC). It had been used as a preliminary cluster sampling method. Random samples of households were taken in the second stage of clustering within each cluster. All subpopulations are fairly represented in the survey results.

The DHS data are open to the public and provide information on maternal, infant, and child mortality, as well as socio-demographic, economic, and health-related variables. We obtained the information from the DHS, which included the location of birth for mothers aged 15 to 49 years, as determined by sampled households in each cluster unit.

\section{Study variables}

The woman questionnaire was used to obtain the dependent variable, which is the place of delivery. The data was gathered from qualified women aged 15 to 49 years old, who were asked questions about their sociodemographic and economic backgrounds (age, sex, education, marital status, and income), birth history, health facility, media exposure, antenatal visits, women and their husbands' job status, and other topics. The dependent variable in this study was registered as a 
dichotomous variable: home delivery (no) and institutional delivery (yes).

The residence of the families residing in; fathers' and mothers' educational status; women's age (in years at the time of the survey); the number of living children inside the family; the existence of mothers' occupation; the household head; the income index; the number of antenatal care (ANC) visits during the pregnancy; the distance between home and health facilities; women's marital status (at the time of the survey); and access to mass media were all considered independent variables. The independent variables are used because they are available in the dataset and have been studied previously. The independent variables were categorize to make the study simpler (Table 2).

\section{Statistical analysis}

The relation between the odds of the place of delivery and the aforementioned explanatory variables was estimated using Pearson chi-square (X2) and logistic regression models. STATA 14 was used to perform the data analysis. At the univariable point, the chi-square test of association was used to statistically test whether there was a meaningful association between the place of delivery and other explanatory categorical variables or not. As an outcome to the logistic regression model, a binary outcome (home delivery (no) or institutional delivery (yes) is used. The availability of a meaningful effect or correlation of independent variables with the outcome variable is tested using a p-value less than 0.05 or $5 \%$.

\section{Ethical considerations}

The data analyses conducted using the publicly available data of the 2013-2017 DHS of nine Sub-Saharan African countries (https://dhsprogram.com/Data/terms-of-use. $\mathrm{cfm})$. The DHS program has given a written permission letter.

Table 1 Year of survey and number of women in the nine SubSaharan Africa using Demographic and Health Surveys 20132017

\begin{tabular}{lll}
\hline Country & Year of survey & Number of women \\
\hline Senegal & 2017 & 3494 \\
Ethiopia & 2016 & 3551 \\
Malawi & 2016 & 3548 \\
Rwanda & 2015 & 3513 \\
Tanzania & 2016 & 3387 \\
Zambia & 2014 & 3525 \\
Namibia & 2013 & 2874 \\
Ghana & 2014 & 3353 \\
Democratic Republic of Congo & 2014 & 3542 \\
Total & & $\mathbf{3 0 7 8 7}$ \\
\hline
\end{tabular}

\section{Results}

A total of 30,787 households were included in nine countries. Ethiopia had a national coverage of institutional delivery for women aged 15 to 49, ranging from 37.9 to $93.5 \%$. Malawi had a national coverage of institutional delivery for women aged 15 to 49 , ranging from $37.9 \%$ to $93.5 \%$. Without taking into account population weighting, the total institutional distribution coverage for all nine countries was $82.3 \%$ (Fig. 1).

\section{Socio-demographic characteristics}

We investigated whether there was a significant relationship between institutional delivery and a variety of categorical independent characteristics in the univariable analyses process. Residence, women's education, age, number of living children, women's occupation, sex of household head, wealth index, number of ANC visits, husband's education, distance from home to health facility, marital status, and media exposure with institutional delivery services all showed statistically significant differences (Table 2).

\section{Determinants of institutional delivery in Sub-Saharan African countries}

In the binary logistic regression model, we examined the possible determinants of institutional services (Table 3). Institutional presence was associated with residency, women's education, women's age, number of living children, women's occupation, household gender, the wealth index, ANC visits, wife education, distance from medical facilities, women's marital status, media exposure, and national variation among women aged 15 to 49 . The odds ratio of the experience of institutional delivery for women living in rural areas vs urban area was 0.44 (95\% confidence interval (CI) 0.41-0.48). Primary educated women were 1.98 (95\% CI 1.85-2.12) times more likely to deliver in health institutes than non-educated women, and secondary and higher educated women were 3.17 (95\% CI 2.88-3.50) times more likely to deliver in health centers with facilities. Women aged 35-49 years were 1.17 (95\% CI 1.05-1.29) times more likely than women aged under 24 years to give birth in health centers. The number of ANC visits: women who visited four or more times were 2.98 (95\% CI 2.77-3.22) times, while women who visited three or less times were twice $(\mathrm{OR}=2.03$; 95\% CI 1.88-2.18) more likely to deliver in health institutes. Distance from home to health facility were 1.18 (95\% CI 1.11-1.25) times; media exposure had 1.28 (95\% CI 1.20-1.36) times more likely than non-mediaexposed women to delivery in health institutions. The odds of distance from home to health facility indicated that as it was not a big problem to deliver in institutions with health facility $(\mathrm{OR}=1.18$; 95\% CI 1.11-1.25). 
Table 2 Relationship between correlates and place of delivery in nine Sub-Saharan Africa

\begin{tabular}{|c|c|c|c|c|}
\hline \multirow[t]{3}{*}{ Variable } & \multicolumn{2}{|c|}{ Place of delivery } & \multirow{3}{*}{$\begin{array}{l}\text { Total } \\
\text { N (\%) }\end{array}$} & \multirow{3}{*}{$\begin{array}{l}p \\
\text { value }\end{array}$} \\
\hline & \multirow{2}{*}{$\begin{array}{l}\text { Home } \\
\mathrm{N}(\%)\end{array}$} & \multirow{2}{*}{$\begin{array}{l}\text { Institutional delivery } \\
\mathrm{N}(\%)\end{array}$} & & \\
\hline & & & & \\
\hline \multicolumn{5}{|l|}{ Residence } \\
\hline Urban & $823(10.2)$ & $8252(36.3)$ & 9075(29) & $<0.001$ \\
\hline Rural & $7,211(89.8)$ & $14,501(63.7)$ & $21,712(71)$ & \\
\hline \multicolumn{5}{|l|}{ Women education } \\
\hline No education & $4048(50.4)$ & $4545(20.0)$ & 8593(28) & $<0.001$ \\
\hline Primary & $3113(38.7)$ & $10,187(44.8)$ & $13,300(43)$ & \\
\hline Secondary and above & $873(10.9)$ & $8021(35.2)$ & 8894(29) & \\
\hline \multicolumn{5}{|l|}{ Age of women in years } \\
\hline $15-24$ & $1981(24.7)$ & $6539(28.7)$ & $8520(28)$ & $<0.001$ \\
\hline $25-34$ & $3840(47.8)$ & $10,986(48.3)$ & $14,826(48)$ & \\
\hline $35-49$ & $2213(27.5)$ & $5228(23.0)$ & $7441(24)$ & \\
\hline \multicolumn{5}{|l|}{ Number of living children } \\
\hline $0-4$ & 4930(61.4) & $17,834(78.4)$ & $22,764(74)$ & $<0.001$ \\
\hline Five and above & 3104(38.6) & 4919(21.6) & $8023(26)$ & \\
\hline \multicolumn{5}{|l|}{ Women occupation } \\
\hline No & $3451(43.0)$ & $7722(34.0)$ & $11,173(36)$ & $<0.001$ \\
\hline Yes & 4583(57.0) & $15,031(56.0)$ & $19,614(64)$ & \\
\hline \multicolumn{5}{|l|}{ Sex of household head } \\
\hline Male & 6488(80.8) & $17,227(75.7)$ & $23,715(77)$ & $<0.001$ \\
\hline Female & 1546(19.2) & $5526(24.3)$ & $7072(23)$ & \\
\hline \multicolumn{5}{|l|}{ Wealth index } \\
\hline Poor & $5637(70.2)$ & 9233(40.6) & $14,870(48)$ & $<0.001$ \\
\hline Middle & 1377(17.1) & $4607(20.2)$ & 5984(19) & \\
\hline Rich & $1020(12.7)$ & 8913(39.2) & 9933(32) & \\
\hline \multicolumn{5}{|l|}{ Number of ANC visit } \\
\hline No antenatal visits & 2884(36.0) & $3193(14.0)$ & $6077(20)$ & $<0.001$ \\
\hline $1-3$ & 2725(33.9) & $7,469(32.8)$ & 10,194(33) & \\
\hline 4 and above & $2425(30.1)$ & $12,091(53.2)$ & $14,516(47)$ & \\
\hline \multicolumn{5}{|l|}{ Husbands education } \\
\hline No education & $3644(45.4)$ & $6382(28.0)$ & $10,026(33)$ & $<0.001$ \\
\hline Primary & 2788(34.7) & $7939(35.0)$ & $10,727(35)$ & \\
\hline Secondary and above & 1602(19.9) & $8432(37.0)$ & $10,034(32)$ & \\
\hline \multicolumn{5}{|l|}{ Distance to a health facility } \\
\hline Big problem & $5280(65.7)$ & $12,503(55.0)$ & $17,783(58)$ & $<0.001$ \\
\hline Not a big problem & 2754(34.3) & $10,250(45.0)$ & $13,004(42)$ & \\
\hline \multicolumn{5}{|l|}{ Marital status } \\
\hline Married & $6311(78.6)$ & $15,436(67.8)$ & $21,747(71)$ & $<0.001$ \\
\hline Others* & $1723(21.4)$ & 7317(32.2) & 9040(29) & \\
\hline \multicolumn{5}{|l|}{ Media exposure } \\
\hline Not exposed & $4494(56.0)$ & $8251(36.3)$ & $12,745(41)$ & $<0.001$ \\
\hline Exposed to mass media & $3540(44.0)$ & $14,501(63.7)$ & $18,041(59)$ & \\
\hline
\end{tabular}

*Single, widowed, divorced 


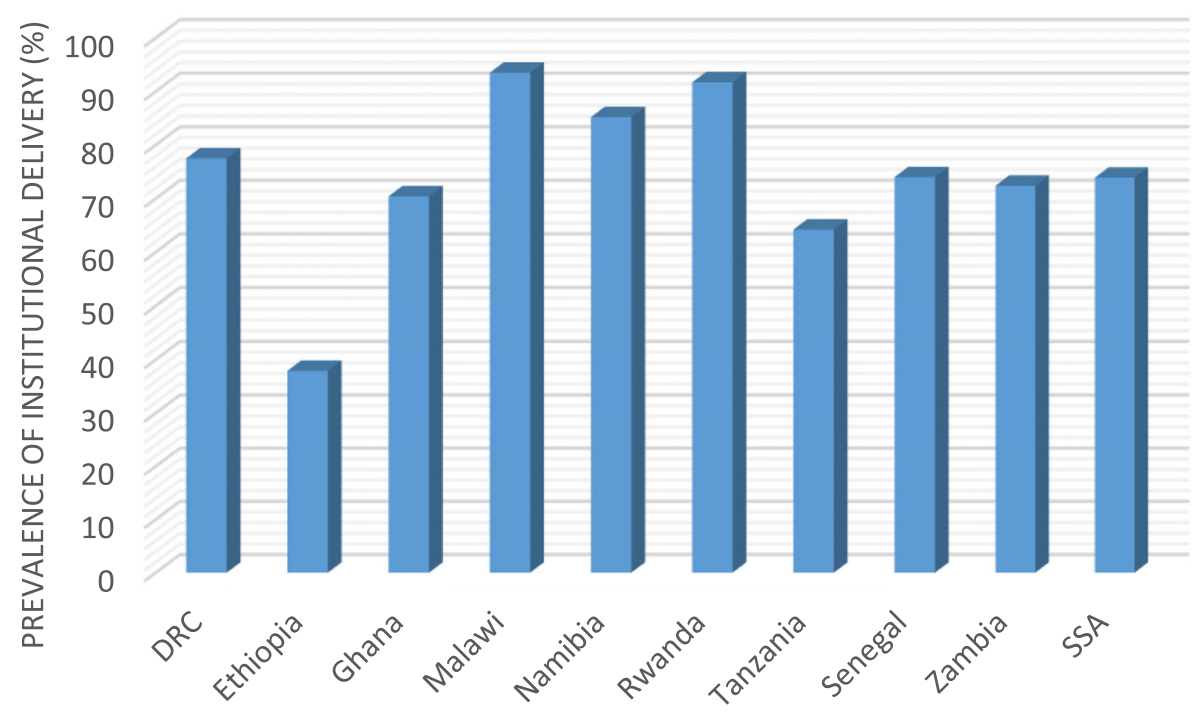

DRC: DEMOCRATIC REPUBLIC OF CONGO SSA: SUB-SAHARAN AFRICA

Fig. 1 The prevalence of institutional delivery in the nine Sub-Saharan Africa countries from 2013 to 2017. DRC: Democratic Republic of Congo

Regarding country-level institutional delivery: Ethiopia (82.3\%), Ghana (30.9\%), Tanzania (47.9\%), Senegal (17.6\%), and Zambia (23.7\%) were less likely to deliver in health institutions than the Democratic Republic of Congo. However, Malawi 4.21 times $(\mathrm{OR}=4.21)$, Namibia 1.7 times $(\mathrm{OR}=1.67)$, and Rwanda 3.23 times $(\mathrm{OR}=3.23)$ more likely delivered in health institutions than the Democratic Republic of Congo (as a reference).

\section{Discussions}

Analyzing the publicly available DHS dataset from nine Sub-Saharan African countries, we have found a nationwide variation of institutional delivery coverage among women aged 15 to 49 years. The institutional delivery can be affected by different socio-demographic and economic characteristics of households. Ethiopia had the lowest use of institutional provision (37.9\%), around 82.3\% lower than the Democratic Republic of Congo. Malawi, however, has the best institutional results, with 4.2 times more than the Democratic Republic of Congo. In Ethiopia and Malawi, the usage of institutional facilities was poor relative to most Sub-Saharan African countries [11]. Non-users of medical facilities made the most significant contribution during pregnancy and childbirth, as well as highest maternal mortality rate was observed in Malawi [12]. Even if increased institutional delivery reduces maternal and neonatal mortality rates, distance, inaccessibility, and a lack of appropriate facilities make it more difficult [3]. It is worse in rural areas than in urban areas. In most nations, trends have resulted in an increase in the delivery of health services.
We found that households with higher educational levels (women and husbands) are more likely to provide institutional care. Previous research has found similar determinants of institutional delivery [12-19]. Parents' educational qualifications and the survival status of their family members are also associated factors. Earlier research has shown that trained mothers are more knowledgeable of child health and hygiene than their non-educated peers. In Sub-Saharan African countries, the death rate for children under the age of five has decreased [20], Malawi and Uganda [21], Madagascar [22], Tanzania [23], and Nigeria [24].

We have investigated that women's age has an effect on institutional provision. The older the woman (35 to 49 years old), the more likely she is to give birth in a hospital. The findings were also consistent with previous research [25] and were linked to only mothers under the age of 40, as well as the youngest (15-19 years) and older (40-49 years) mothers. It is difficult to draw broad conclusions based on the age of women and the success of institutions. Women's age, on the other hand, has been related to institutional service delivery in studies. The health care facility's service was deteriorating as women grew older [26-29].

The findings revealed that the more live children in a household, the lower the institutional delivery of mothers was statistically important. This is because having a bigger family may have a negative impact on the household's economic situation. In health facilities, working women are administered more often than women who are not employed. 
Table 3 Multivariable logistic regression analysis of factors associated with institutional delivery in Sub-Saharan Africa countries from 2013 to 2017

\begin{tabular}{|c|c|c|}
\hline \multirow[t]{2}{*}{ Variable } & \multicolumn{2}{|c|}{ Institutional delivery } \\
\hline & $\begin{array}{l}\text { Odds } \\
\text { ratio }\end{array}$ & $\begin{array}{l}\text { 95\% confidence } \\
\text { interval }\end{array}$ \\
\hline \multicolumn{3}{|l|}{ Residence } \\
\hline Urban & 1 & \\
\hline Rural & $0.44^{*}$ & $0.41-0.48$ \\
\hline \multicolumn{3}{|l|}{ Women education } \\
\hline No education & 1 & \\
\hline Primary & $1.98^{*}$ & $1.85-2.12$ \\
\hline Secondary and above & $3.17^{*}$ & $2.88-3.50$ \\
\hline \multicolumn{3}{|l|}{ Age of women in years } \\
\hline $15-24$ & 1 & \\
\hline $25-34$ & 1.01 & $0.94-1.09$ \\
\hline $35-49$ & $1.17^{*}$ & $1.05-1.29$ \\
\hline \multicolumn{3}{|l|}{ Number of living children } \\
\hline $0-4$ & 1 & \\
\hline Five and above & $0.61^{*}$ & $0.56-0.66$ \\
\hline \multicolumn{3}{|l|}{ Women occupation } \\
\hline Housewife & 1 & \\
\hline Employed & $1.34^{*}$ & $1.26-1.43$ \\
\hline \multicolumn{3}{|l|}{ Sex of household head } \\
\hline Male & 1 & \\
\hline Female & $1.14^{*}$ & $1.05-1.23$ \\
\hline \multicolumn{3}{|l|}{ Wealth index } \\
\hline Poor & 1 & \\
\hline Middle & $1.36^{*}$ & $1.26-1.47$ \\
\hline Rich & $2.15^{*}$ & $1.97-2.35$ \\
\hline \multicolumn{3}{|l|}{ Number of ANC visit } \\
\hline No antenatal visits & 1 & \\
\hline $1-3$ & $2.03^{*}$ & $1.88-2.18$ \\
\hline Four and above & $2.98^{*}$ & $2.77-3.22$ \\
\hline \multicolumn{3}{|l|}{ Husbands education } \\
\hline No education & 1 & \\
\hline Primary & $1.32^{*}$ & $1.23-1.42$ \\
\hline Secondary and above & $1.22^{*}$ & $1.12-1.32$ \\
\hline \multicolumn{3}{|c|}{ Distance to a health facility } \\
\hline Big problem & 1 & \\
\hline Not a big problem & $1.18^{*}$ & $1.11-1.25$ \\
\hline \multicolumn{3}{|l|}{ Marital status } \\
\hline Married & 1 & \\
\hline Others ${ }^{* *}$ & $1.33^{*}$ & $1.24-1.43$ \\
\hline \multicolumn{3}{|l|}{ Media exposure } \\
\hline Not exposed & 1 & \\
\hline Exposed to mass media & $1.28^{*}$ & $1.20-1.36$ \\
\hline
\end{tabular}

Table 3 Multivariable logistic regression analysis of factors associated with institutional delivery in Sub-Saharan Africa countries from 2013 to 2017 (Continued)

\begin{tabular}{lll}
\hline Variable & \multicolumn{2}{l}{ Institutional delivery } \\
\cline { 2 - 3 } $\begin{array}{l}\text { Odds } \\
\text { ratio }\end{array}$ & $\begin{array}{l}\text { 95\% confidence } \\
\text { interval }\end{array}$ \\
\hline $\begin{array}{l}\text { Country } \\
\text { Cemocratic Republic of }\end{array}$ & 1 & \\
Ethiopia & $0.18^{*}$ & $0.16-0.20$ \\
Ghana & $0.69^{*}$ & $0.62-0.77$ \\
Malawi & $4.21^{*}$ & $3.60-4.92$ \\
Namibia & $1.67^{*}$ & $1.47-1.90$ \\
Rwanda & $3.23^{*}$ & $2.80-3.73$ \\
Tanzania & $0.52^{*}$ & $0.47-0.58$ \\
Senegal & $0.82^{*}$ & $0.74-0.92$ \\
Zambia & $0.76^{*}$ & $0.68-0.85$ \\
\hline *Significant association & &
\end{tabular}

* Significant association

Women's households have greater health care practices than men's households, according to the findings. It may imply the possibility that males can save their own lives and those of their families. The findings also revealed a statistical connection between the wealth index's status and institutional delivery. The higher a family's income is, the higher a woman's income is. Their husbands or other members of their household made decisions based on a lack of financial resources for women, especially in rural areas, which could have an effect on their provision [30-32]. As a result, we might conclude that earnings had the ability to influence where mothers would give birth.

The results revealed that ANC visits are statistically significantly associated with institutional implementation. Women who frequented health facilities prior to delivery may have had an effect on health care. Women who have more ANC visits during their pregnancy are more likely to have ANC visits to health institutions than women who do not have ANC visits [33], at least once [17].

The findings revealed that distance to health care facilities was not a problem. According to our research, the number of single (unpaired) women is higher than the number of married women (paired). The media plays a critical role in the community's social, economic, and political issues. During our investigation, women from media-exposed groups were found to be significantly associated with institutional growth. Different institutions performed differently across countries. 


\section{Conclusion}

The United Nations (UN) [34] published on a nation's general health and well-being as a proxy for children's and mothers' health in 2010. Maternal health and child survival are two sides of the same coin; one cannot exist without the other. Mothers' and children's mortality and morbidity can be minimized if proper treatment is taken during pregnancy, childbirth, and postnatal care.

Countries planned and collected data on the assessment of female data at each level of the DHS program, including how women receive treatment (during pregnancy, at work, during childbirth, and in the postnatal period) by asking questions about prenatal, labor, and postnatal delivery of women aged 15 to 49 who had given birth in the previous 5 years.

When women become sick, a variety of factors may make it difficult for them to seek medical help. The knowledge on such determinant factors is particularly important in order to recognize and resolve the inequalities that women may face in obtaining treatment prior to childbirth, during pregnancy, and after birth. The DHS survey of 9 African Sub-Saharan women aged 15 to 49 to see if any of the following variables presented a significant problem during childbirth: distance from the health care center, pre-presentation visits to the health center (ANC), and media exposure.

Women who gave birth in health care facilities accounted for $74 \%$ of the total, while the rest $(26 \%)$ gave birth in the absence of such facilities. In terms of country-level comparisons, Ethiopia has the smallest institutional delivery (37.1\%) and Malawi has the largest institutional delivery (93.5\%). Women: over 24, at least elementary school, urban, less children; never married (live alone); higher prenatal care visits; increased economic status; had a chance to attend the mass media; had more chances than others to give birth to literary husbands in health-care institutions. Working women were more likely than unemployed women to give birth to their babies with good health facility. A big problem was listed by approximately $58 \%$ of respondents; the remaining $(42 \%)$ did not mention a big problem in the choice of the place of delivery of childhood.

The sub-regional member states should make additional efforts to meet the national and international targets set out in the Sustainable Development Goals (SDG) for reducing maternal mortality by 2030 . As a result, the challenges of closing the gap between urban and rural health care, improving women's educational levels, expanding the number of health care institutions, and raising awareness of visiting and giving birth in health care facilities must all be tackled.

\section{Abbreviations}

ANC: Antenatal care; DHS: Demographic and Health Survey; MMR: Maternal mortality rate; OR: Odds ratio; PHC: Population and Housing Census; SDG: Sustainable Development Goals

\section{Acknowledgements}

Not applicable.

\section{Authors' contributions}

SG conducted a literature search, planned the study, carried out data extraction, performed data analysis and interpretation, and drafted the manuscript. SM carried out data extraction. Both authors read and approved the final manuscript.

\section{Funding}

No fund.

\section{Availability of data and materials}

In accordance with IRB-approved DHS public-use data settings, the data sets analyzed during the current study are available and did not enable respondents, families, or sample communities to be identified in any way. The data files do not contain names of people or household addresses. Only regional levels can be achieved by geographical identifiers (where regions are typically very large geographical areas covering several countries/provinces). There is a PSU number in the data file in each enumeration area (primary sampling unit), but there are no PSU numbers which indicate names or locations. The coordinates are for the entire enumeration area, and not individual households, only in surveys that collect GIS in the field, and the measured coordinates are randomly dispatched within a large geo-area, thus preventing the identification of particular enumeration areas.

\section{Declarations}

Ethics approval and consent to participate Not applicable.

\section{Consent for publication}

Not applicable.

\section{Competing interests}

The authors declared that they have no competing interests.

Received: 16 February 2021 Accepted: 19 May 2021

Published online: 26 May 2021

\section{References}

1. Mehari AM. Levels and determinants of use of institutional delivery care services among women of childbearing age in Ethiopia: analysis of EDHS 2000 and 2005 data. ICF International. 2013.

2. Palamuleni M. Determinants of non-institutional deliveries in Malawi. Malawi Med J. 2011:23(4):104-8.

3. Central Statistical Agency (CSA) [Ethiopia] and ICF. Ethiopia Demographic and Health Survey 2016. Addis Ababa, Ethiopia, and Rockville, Maryland, USA: CSA and ICF. 2016.

4. Mrisho M, Schellenberg JA, Mushi AK, Obrist B, Mshinda H, Tanner M, et al. Factors affecting home delivery in rural Tanzania. Tropical medicine \& international health. 2007;12(7):862-72. https://doi.org/10.1111/j.1365-3156.2 007.01855.x.

5. Mekonnen $Y$, Mekonnen A. Factors influencing the use of maternal healthcare services in Ethiopia. J Health Popul Nutr. 2003:374-82.

6. Yaya S, Idriss-Wheeler D, Shibre G, Amouzou A, Bishwajit G. Prevalence of institutional delivery and its correlates amongst women of reproductive age in Mozambique: a cross-sectional analysis. Reprod Health. 2020;17:1-11.

7. Yoseph M, Abebe SM, Mekonnen FA, Sisay M, Gonete KA. Institutional delivery services utilization and its determinant factors among women who gave birth in the past 24 months in Southwest Ethiopia. BMC Health Serv Res. 2020:20(1):265. https://doi.org/10.1186/s12913-020-05121-9.

8. Ababulgu FA, Bekuma TT. Delivery Site Preferences and Associated Factors among Married Women of Child-Bearing Age in Bench Maji Zone, Ethopia. Ethiop J Health Sci. 2016;26(1):45-54. https://doi.org/10.4314/ejhs.v26i1.9. 
9. Olorunsaiye CZ, Degge HM, Lengmang SJ. Age-specific factors related to institutional delivery in Nigeria: Insights from the 2011 Multiple Indicator Cluster Survey. Women Health. 2018;58(9):1001-16. https://doi.org/10.1080/ 03630242.2017.1377801.

10. A. R. Bado and A. Sathiya Susuman. Women's education and health inequalities in under-five mortality in selected subSaharan African countries, 1990-2015. PLoS One. 2016; vol. 11, no. 7, Article ID e0159186.

11. Andriano L, Monden CWS. The causal effect of maternal education on child mortality: evidence from a quasi-experiment in Malawi and Uganda. Demography. 2019;56(5):1765-90. https://doi.org/10.1007/s13524-019-00812-3.

12. S. Badji. Mother's Education and Increased Child Survival in Madagascar: What Can We Say?, Groupe d'Analyse et de eorie Economique, Ecully, France. 2016.

13. Nattey C, Masanja H, Klipstein-Grobusch K. Relationship between household socio-economic status and under-five mortality in Rufiji DSS, Tanzania. Global Health Action. 2013;6(1):19278. https://doi.org/10.3402/gha.v6i0.19278.

14. Uthman OA, Uthman MB, Yahaya I. A population-based study of effect of multiple birth on infant mortality in Nigeria. BMC Pregnancy and Childbirth. 2008;8(1):41. https://doi.org/10.1186/1471-2393-8-41.

15. Fantahun M. Factors affecting ANC attendants and preference of delivery by pregnancy women in Gulale Woreda. Ethio j Health Dev. 1992;6(2):17-22.

16. Mrisho M. Factors affecting home delivery in rural Tanzania. Trop Med Int Health. 2007:4(2):62-72.

17. Hounton S, Chapman G, Ronsmans C. Accessibility and utilization of delivery care within a skilled care initiative in rural Burkina Faso. Trop Med Int Health. 2008;6(3):44-52.

18. Fekadu A, Yitayal M, Alemayehu GA, Abebe SM, Ayele TA, Tariku A, Andargie G, Teshome DF, Gelaye KA. Frequent Antenatal Care Visits Increase Institutional Delivery at Dabat Health and Demographic Surveillance System Site, Northwest Ethiopia. J Pregnancy. 2019; Article ID 1690986, 6 pages, 2019. https://doi.org/10.1155/2019/1690986.

19. World Health Organization (WHO), United Nations Children's Fund (UNICEF), United Nations Population Fund (UNFPA), World Bank Group, United Nations Population Division. Trends in maternal mortality: 2000 to 2017: estimates by WHO, UNICEF, UNFPA, World Bank Group, and the United Nations Population Division. Geneva: World Health Organization; 2019.

20. World Health Organization. Sexual and reproductive health. 2019. https:// www.who.int/reproductivehealth/maternal-mortality-2000-2017/en/.

21. Kenya National Bureau of Statistics, Ministry of Health/Kenya, National AIDS Control Council/Kenya, Kenya Medical Research Institute, National Council for Population and Development/Kenya, and ICF International. Kenya Demographic and Health Survey 2014. Rockville, MD, USA: Kenya National Bureau of Statistics, Ministry of Health/Kenya, National AIDS Control Council/ Kenya, Kenya Medical Research Institute, National Council for Population and Development/Kenya, and ICF International. 2015.

22. Ghana Statistical Service - GSS, Ghana Health Service - GHS, and ICF International. Ghana Demographic and Health Survey 2014. Rockville, Maryland, USA: GSS, GHS, and ICF International. 2015.

23. Ministry of Health, Community Development, Gender, Elderly and Children (MoHCDGEC) [Tanzania Mainland], Ministry of Health $(\mathrm{MoH})$ [Zanzibar], National Bureau of Statistics (NBS), Office of the Chief Government Statistician (OCGS), and ICF. Tanzania Demographic and Health Survey and Malaria Indicator Survey (TDHS-MIS) 2015-16. Dar es Salaam, Tanzania, and Rockville, Maryland, USA: MoHCDGEC, MoH, NBS, OCGS, and ICF. 2016.

24. The Center for Strategic and International Studies. Charitynavigator.org. March 1, 2018. Retrieved September 11, 2018.

25. Chireshe J, Ocran MK. Financial development and health care expenditure in Sub Saharan Africa countries. Cogent Econ Fin. 2020;8:1. https://doi.org/1 0.1080/23322039.2020.1771878.

26. Feyissa TR, Genemo GA. Determinants of institutional delivery among childbearing age women in Western Ethiopia, 2013: Unmatched case-control study. PLoS One. 2014;9(5):e97194. https://doi.org/10.1371/journal.pone.0097194.

27. Onah HE, Ikeako LC, Iloabachie GC. Factors associated with the use of maternity services in Enugu, southeastern Nigeria. Social Sci Med. 2006; 63(7):1870-8. https://doi.org/10.1016/j.socscimed.2006.04.019.

28. Idris SH, Gwarzo UMD, Shehu AU. Determinants of place of delivery among women in a semi-urban settlement in Zaria, northern Nigeria. Ann Afr Med. 2006;5(2):68-72.

29. Feleke H, Mirkuzie W, Fikru T. Predictors of institutional delivery in Sodo town, Southern Ethiopia. Afr J Prim Health Care Fam Med. 2013;5(1):544
30. Tura G, Afework MF, Yalew AW. The effect of birth preparedness and complication readiness on skilled care use: A prospective follow-up study in Southwest Ethiopia. Reprod Health. 2014;11(1):60. https://doi.org/10.1186/1742-4755-11-60.

31. Kebede B, Gebeyehu A, Andargie G. Use of previous maternal health services has a limited role in reattendance for skilled institutional delivery: Crosssectional survey in Northwest Ethiopia. Int J Womens Health. 2013;5(1):79-85.

32. Fekadu M, Regassa N. Skilled delivery care service utilization in Ethiopia: Analysis of rural-urban differentials based on national demographic and health survey (DHS) data. Afr Health Sci. 2014;14(4):967-73.

33. Adedokun ST, Uthman OA. Women who have not utilized health Service for Delivery in Nigeria: who are they and where do they live?. BMC Pregnancy Childbirth. 2019; 19, 93. https:/doi.org/https:/doi.org/10.1186/s12884-019-2242-6

34. United Nations (UN) Secretary-General. 2010. Global Strategy for Women's and Children's Health. New York: The Partnership for Maternal, Newborn and Child Health. New York. http://www.who.int/pmnch/knowledge/publica tions/fulldocument_globalstrategy/en.

\section{Publisher's Note}

Springer Nature remains neutral with regard to jurisdictional claims in published maps and institutional affiliations.
Ready to submit your research? Choose BMC and benefit from:

- fast, convenient online submission

- thorough peer review by experienced researchers in your field

- rapid publication on acceptance

- support for research data, including large and complex data types

- gold Open Access which fosters wider collaboration and increased citations

- maximum visibility for your research: over $100 \mathrm{M}$ website views per year

At BMC, research is always in progress.

Learn more biomedcentral.com/submissions 